\section{Stability of Extemporaneously Compounded Amlodipine Besylate Oral Suspensions}

Amlodipine is a calcium-channel blocker often used to treat hypertension in adults and children. ${ }^{1-4}$ In Canada, amlodipine is available as tablets containing a quantity of amlodipine besylate (molar mass $567.05 \mathrm{~g} / \mathrm{mol}$ ) equivalent to $2.5 \mathrm{mg}, 5 \mathrm{mg}$, or $10 \mathrm{mg}$ of amlodipine base (molecular weight 408.87). Nahata and others ${ }^{5}$ reported the stability of compounded amlodipine besylate suspensions in 1999 . The suspensions, containing the equivalent of $1 \mathrm{mg} / \mathrm{mL}$ of amlodipine base, were prepared from commercial tablets using either a 1:1 mixture of methylcellulose $1 \%$ and syrup or a 1:1 mixture of OraPlus and OraBlend vehicles (Perrigo, Dublin, Ireland). The authors concluded that both preparations were stable when stored in plastic prescription bottles for up to 91 days at $4^{\circ} \mathrm{C}$ and for up to 56 days at $25^{\circ} \mathrm{C} .^{5}$

The current study was undertaken to evaluate the stability of amlodipine besylate suspensions (equivalent to amlodipine base $1 \mathrm{mg} / \mathrm{mL}$ ) in dye-free Oral Mix vehicle at $5^{\circ} \mathrm{C}$ and $25^{\circ} \mathrm{C}$ for up to 90 days.

Amlodipine besylate suspensions were prepared by diluting bulk amlodipine besylate (346.7 mg, USP grade; Medisca Pharmaceutique Inc, Montréal, Quebec; lot 46892/A, expiry March 2016) with glycerol $(500 \mu \mathrm{L}, 99.5 \%$ grade; Sigma-Aldrich, Oakville, Ontario; lot TU 02342LU) and then bringing to a final volume of $250 \mathrm{~mL}$ with Oral Mix vehicle (Medisca Pharmaceutique Inc; lot 1185/A, expiry January 2018). This preparation resulted in a concentration equivalent to $1 \mathrm{mg} / \mathrm{mL}$ of amlodipine base. Similar suspensions were prepared from amlodipine besylate tablets ( $46 \times$ 5-mg Norvasc tablets; Pfizer, Kirkland, Quebec; lot D10047232, expiry January 2017). The tablets were first ground with a mortar and pestle, and the resulting powder was then diluted with Oral Mix to the required final volume of $230 \mathrm{~mL}$. Each preparation was packaged in 6 amber glass serum bottles (fill volume $30 \mathrm{~mL}$; Wheaton type 1, Medisca Pharmaceutique Inc; lot 24908/A) and 42 amber plastic syringes (fill volume $1 \mathrm{~mL}$; PreciseDose Dispenser [lot 55052/A] and W/Tip cap [lot 46968/C], Medisca Pharmaceutique Inc). Three of the bottles and 21 of the syringes were refrigerated at $5^{\circ} \mathrm{C} \pm 2^{\circ} \mathrm{C}$ and ambient relative humidity for up to 90 days, and the remainder of the containers were incubated at $25^{\circ} \mathrm{C} \pm 2^{\circ} \mathrm{C}$ and $60 \% \pm 5 \%$ relative humidity for up to 90 days (Forma 3911 environmental chamber, Thermo Scientific, Rochester, New York). The remaining volume of each preparation was used for time zero analyses.
During the stability study, samples were examined for colour and odour change, as well as redispersibility, on days $0,14,30,45$, 60,75 , and 90 . On these predetermined days, a $1-\mathrm{mL}$ aliquot was sampled from each bottle and 3 syringes were retrieved from each stability chamber for analysis by high-performance liquid chromatography (HPLC) with ultraviolet (UV) detection.

Each HPLC injection sample was prepared by diluting $50 \mu \mathrm{L}$ of the test preparation with $950 \mu \mathrm{L}$ of a 20:80 mixture of HPLCgrade acetonitrile (Fisher Scientific, Ottawa, Ontario; lot 141693) and purified water (Milli-Q Synthesis A10 system, Millipore, Etobicoke, Ontario). The resulting mixture was vortexed (20 s; Vortex Genie 2, Scientific Industries Inc, Bohemia, New York) and centrifuged (10 $000 \mathrm{rpm}$ for $10 \mathrm{~min}$; Centrifuge 5424, Eppendorf, Mississauga, Ontario). The supernatant of each sample was collected and dispensed into 2 wells $(270 \mu \mathrm{L}$ each) of a 96-well plate (0.5-mL volume wells, PK20 plates, VWR International, Randor, Pennsylvania). After the addition of samples, the plates were sealed and immediately subjected to HPLC analysis (pre-slit silicon well cap for 96-well plate, Thermo Scientific).

Calibration samples were prepared in a 20:80 mixture of acetonitrile and water using amlodipine besylate at concentrations equivalent to $0.25,0.50,0.75,1.00,1.50$, and $2.00 \mathrm{mg} / \mathrm{mL}$ amlodipine base.

Forced degradation was performed by mixing a preparation of amlodipine besylate in Oral Mix ( $1 \mathrm{~mL}$ of a solution equivalent to $2 \mathrm{mg} / \mathrm{mL}$ amlodipine base) with hydrochloric acid (1 mL of a $1 \mathrm{~mol} / \mathrm{L}$ solution; Fisher Scientific; lot 143309) and separately with a hydrogen peroxide solution $(1 \mathrm{~mL}$ of a $3 \%$ solution; Fisher Scientific; lot 135515). These mixtures were then heated at $70^{\circ} \mathrm{C}$ for $3 \mathrm{~h}$. After cooling, HPLC injection samples were prepared as described above.

HPLC analyses were performed using a Prominence UFLC system (Shimadzu Scientific Instruments, Laval, Quebec), consisting of an LC-20AD binary pump, a DGU-20A5 solvent degasser, an SIL-20AC HT refrigerated autosampler set at $10^{\circ} \mathrm{C}$ (injection volume $10 \mu \mathrm{L}$ ), a CTO-20AC column oven set at $40^{\circ} \mathrm{C}$, a reversephase C18 column (Kinetex XB C18 column, $4.6 \times 100$ mm, $5 \mu \mathrm{m}$, Phenomenex, Torrance, California; lot 5705-26), and an SPD-M20A multiple-wavelength photodiode array with UV detection wavelength of $238 \mathrm{~nm}$. Sealed multiwell plates were used to store the samples, and duplicate injections were performed from separate wells. The isocratic mobile phase was composed of $33 \%$ acetonitrile and $67 \%$ aqueous potassium phosphate monobasic 
Table 1. Chemical Stability of Amlodipine Besylate in Suspension Prepared from Bulk Powder

\begin{tabular}{|c|c|c|}
\hline \multirow[b]{2}{*}{ Study Day } & \multicolumn{2}{|c|}{ Mean Concentration \pm SD $(\mathrm{mg} / \mathrm{mL})$ and Mean $\%$ Remaining* } \\
\hline & Packaged in Amber Glass Bottles & Packaged in Amber Plastic Syringes \\
\hline \multicolumn{3}{|c|}{ Storage at $5^{\circ} \mathrm{C}$, ambient $\mathrm{RH}$} \\
\hline Initial & $1.02 \pm 0.03(100.0)$ & $1.02 \pm 0.03(100.0)$ \\
\hline 14 & $1.03 \pm 0.02(100.8)$ & $1.06 \pm 0.03(104.0)$ \\
\hline 30 & $1.03 \pm 0.01 \quad(101.5)$ & $1.03 \pm 0.01 \quad(101.7)$ \\
\hline 45 & $1.01 \pm 0.00$ & $0.99 \pm 0.02 \quad(97.6)$ \\
\hline 60 & $1.00 \pm 0.02 \quad(98.6)$ & $1.02 \pm 0.01 \quad(100.3)$ \\
\hline 75 & $1.02 \pm 0.01 \quad(100.0)$ & $1.01 \pm 0.01 \quad(99.4)$ \\
\hline 90 & $1.00 \pm 0.03 \quad(98.1)$ & $0.99 \pm 0.01$ \\
\hline \multicolumn{3}{|c|}{ Storage at $25^{\circ} \mathrm{C}, 60 \% \mathrm{RH}$} \\
\hline Initial & $1.02 \pm 0.03 \quad(100.0)$ & $1.02 \pm 0.03 \quad(100.0)$ \\
\hline 14 & $0.98 \pm 0.02 \quad(96.7)$ & $1.00 \pm 0.01$ \\
\hline 30 & $0.97 \pm 0.01$ & $0.97 \pm 0.00$ \\
\hline 45 & $0.93 \pm 0.00$ & $0.94 \pm 0.00$ \\
\hline 60 & $0.94 \pm 0.02$ & $0.93 \pm 0.01$ \\
\hline 75 & $0.89 \pm 0.01$ & $0.91 \pm 0.01$ \\
\hline 90 & $0.85 \pm 0.01$ & $0.88 \pm 0.02$ \\
\hline
\end{tabular}

$\mathrm{RH}=$ relative humidity, $\mathrm{SD}=$ standard deviation.

* Mean concentrations in equivalent of amlodipine base are based on 3 separate samples

each analyzed in duplicate; the percentage remaining is relative to the initial concentration.

Table 2. Chemical Stability of Amlodipine Besylate in Suspension Prepared from Tablets

\begin{tabular}{|c|c|c|}
\hline \multirow[b]{2}{*}{ Study Day } & \multicolumn{2}{|c|}{ Mean Concentration \pm SD $(\mathrm{mg} / \mathrm{mL})$ and Mean \% Remaining* } \\
\hline & Packaged in Amber Glass Bottles & Packaged in Amber Plastic Syringes \\
\hline \multicolumn{3}{|c|}{ Storage at $5^{\circ} \mathrm{C}$, ambient $\mathrm{RH}$} \\
\hline Initial & $0.96 \pm 0.03(100.0)$ & $0.96 \pm 0.03 \quad(100.0)$ \\
\hline 14 & $0.97 \pm 0.04 \quad(101.4)$ & $0.97 \pm 0.02(101.1)$ \\
\hline 30 & $0.97 \pm 0.01 \quad(100.9)$ & $0.97 \pm 0.02(101.2)$ \\
\hline 45 & $0.97 \pm 0.03 \quad(101.0)$ & $0.92 \pm 0.00 \quad(95.8)$ \\
\hline 60 & $0.98 \pm 0.00 \quad(102.2)$ & $0.96 \pm 0.05 \quad(100.3)$ \\
\hline 75 & $0.95 \pm 0.02 \quad(99.5)$ & $0.92 \pm 0.02 \quad(96.0)$ \\
\hline 90 & $0.95 \pm 0.01$ & $0.96 \pm 0.03(100.0)$ \\
\hline \multicolumn{3}{|c|}{ Storage at $25^{\circ} \mathrm{C}, 60 \% \mathrm{RH}$} \\
\hline Initial & $0.96 \pm 0.03(100.0)$ & $0.96 \pm 0.03 \quad(100.0)$ \\
\hline 14 & $0.96 \pm 0.03 \quad(100.0)$ & $0.91 \pm 0.01$ \\
\hline 30 & $0.98 \pm 0.04 \quad(102.1)$ & $0.89 \pm 0.01$ \\
\hline 45 & $0.92 \pm 0.01$ & $0.87 \pm 0.02$ \\
\hline 60 & $0.90 \pm 0.00$ & $0.86 \pm 0.02$ \\
\hline 75 & $0.86 \pm 0.04$ & $0.83 \pm 0.02$ \\
\hline 90 & $0.87 \pm 0.02$ & $0.84 \pm 0.07$ \\
\hline
\end{tabular}

$\mathrm{RH}=$ relative humidity, SD $=$ standard deviation.

* Mean concentrations in equivalent of amlodipine base are based on 3 separate samples each analyzed in duplicate; the percentage remaining is relative to the initial concentration.

solution $10 \mathrm{mmol} / \mathrm{L}$ (J T Baker, Phillipsburg, New Jersey; lot Y22465) and was eluted at $1 \mathrm{~mL} / \mathrm{min}$. Quantification was performed by evaluating the area of the amlodipine peak.

Testing of linearity of the HPLC method between 0 and $2 \mathrm{mg} / \mathrm{mL}$ using the calibration samples resulted in $r^{2}$ of 0.9999 . A sample preparation recovery of $102 \% \pm 3 \%$ was calculated by comparing samples of amlodipine besylate in Oral Mix with samples of amlodipine besylate in a 20:80 mixture of acetonitrile and water at concentrations equivalent to $1 \mathrm{mg} / \mathrm{mL}$ of amlodipine base. Intraday and interday coefficients of variation were calculated from samples prepared from amlodipine besylate at concentrations equivalent to $0.75,1.00$, and $1.50 \mathrm{mg} / \mathrm{mL}$ of amlodipine base. These samples were evaluated in triplicate on 3 consecutive days. Intraday coefficients of variation calculated from 3 injections on the first day were $0.37 \%, 0.61 \%$, and $0.16 \%$ at $0.75,1.00$, and $1.50 \mathrm{mg} / \mathrm{mL}$, respectively. Interday coefficients of variation calculated from the first injection on 3 consecutive days were $1.38 \%, 1.58 \%$, and $1.10 \%$, respectively. 
The forced degradation experiments resulted in recovery of $10.3 \%$ and $34.5 \%$ of the amlodipine signal in acidic conditions and oxidative conditions, respectively. Amlodipine retention time was about $4.4 \mathrm{~min}$, and the peak for amlodipine was clearly separated from peaks for excipients and degradation products, which all eluted between 0.9 and $3.8 \mathrm{~min}$.

Throughout the stability study, all of the suspensions could be easily resuspended. No notable change in colour or odour was observed. Formulations prepared from bulk amlodipine besylate and from tablets and stored at $5^{\circ} \mathrm{C}$ maintained not less than $90 \%$ of their initial concentration after 90 days (Tables 1 and 2). With storage at $25^{\circ} \mathrm{C}$, preparations made from bulk powder remained stable for 60 days in both types of storage container, whereas formulations prepared from tablets were stable for 60 days in bottles and 45 days in syringes.

In conclusion, amlodipine besylate suspensions equivalent to $1 \mathrm{mg} / \mathrm{mL}$ of amlodipine base in Oral Mix prepared from bulk powder were stable for up to 90 days at $5^{\circ} \mathrm{C}(98.1 \%$ remaining in bottles and $97.3 \%$ remaining in syringes) and 60 days at $25^{\circ} \mathrm{C}$ (92.1\% remaining in bottles and $91.5 \%$ remaining in syringes). Suspensions prepared from tablets were also stable for 90 days at $5^{\circ} \mathrm{C}(99.0 \%$ remaining in bottles and $100.0 \%$ remaining in syringes), but with storage at $25^{\circ} \mathrm{C}$, these suspensions were stable for only 60 days in bottles (94.2\% remaining) and 45 days in syringes (91.0\% remaining). These results are comparable to the results obtained by Nahata and others ${ }^{5}$ using other aqueous vehicles.

References

1. Flynn JT, Smoyer WE, Bunchman TE. Treatment of hypertensive children with amlodipine. Am J Hypertens. 2000;13(10):1061-6.

2. Sahney S. A review of calcium channel antagonists in the treatment of pediatric hypertension. Pediatr Drugs. 2006;8(6):357-73.

3. Tallian KB, Nahata MC, Turman MA, Mahan JD, Hayes JR, Mentser MI. Efficacy of amlodipine in pediatric patients with hypertension. Pediatr Nephrol. 1999; 13(4):30410.

4. Andersen J, Groshong T, Tobias JD. Preliminary experience with amlodipine in the pediatric population. Am J Therapeut. 2006;13(3):198-204.

5. Nahata MC, Morosco RS, Hipple TF. Stability of amlodipine besylate in two liquid dosage forms. J Am Pharm Assoc (Wash). 1999;39(3):375-7.

Mihaela Friciu, MSC

Research Associate

Sarra Zaraa, MSc

Research Associate

Grégoire Leclair, BPharm, PhD

Associate Professor

Faculty of Pharmacy

Université de Montréal

Montréal, Quebec

Competing interests: None declared.

Funding: This study was funded by an unrestricted grant from Medisca Pharmaceutique Inc. 